\title{
Effect of COVID-19 on cochlear implant users: parental perspectives
}

\author{
Udit Saxena', Gish Chacko', S B Rathna Kumar², Vikas Nagabathula', Venkata Damarla' \\ ${ }^{1}$ Department of Audiology, MAA Institute of Speech \& Hearing, Hyderabad, India; ${ }^{2}$ Department of Audiology, Ali Yavar Jung National Institute of \\ Speech and Hearing Disabilities (Divyangjan), Bandra (west), Mumbai, India
}

Purpose: For ten months the world has witnessed a global pandemic "COVID-19", which disturbed many lives either directly and/or indirectly. COVID-19 has proven challenging to the public health system and considering the hearing healthcare, an internet-based survey was conducted on how COVID-19 affected the services to Cochlear Implant users and which consecutively affected their communication needs.

Methods: The study was carried out during the period of June-August 2020. The questionnaire consisted of 38 questions, developed and presented via "Google forms". The questions were based on the common problems faced by the Cochlear Implant users. The nature of the questions was generally focused on how COVID-19 affected their child's communication due to limited services. The questionnaire was self-administered and the time taken would be 10-15 minutes. The parents of the Cochlear Implanted children were asked to answer the survey with the best of their experience.

Results: The overall survey results showed that majority of the respondents observed a variety of problems related to the usage, management and maintenance of Cochlear Implant during this COVID-19 pandemic condition.

Conclusions: This report suggests that hearing health care requires a radical rethinking of service delivery and create the momentum to rapidly formulate innovative digital and telehealth approaches in response to these changing situations.

Keywords: COVID-19, Survey, Cochlear implant (CI), Hearing services, Auditory verbal therapy (AVT), Personal protective equipment (PPE)

\section{INTRODUCTION}

For ten months the world has witnessed a global pandemic - COVID-19, which disturbed many lives either directly and/or indirectly. Coronavirus disease 2019 (COVID-19) is an acute respiratory illness caused by the newly identified $\beta$-coronavirus SARS-CoV-2 virus [1]. At nearly 41.9 million cases worldwide, the pandemic is a global public health emergency [2]. As there is no vaccine or treatment, 'social distancing' or reducing interpersonal and community interaction, may be the only way to minimize disease transmission.

COVID-19 has proven challenging to the public health system, as a consequence, is having an impact on mental health; further health problems due to the collective concerns, such as stress, anxiety, depression, insomnia [3]. In these frightful circumstances additional attention should be given to people with impairments, such as hearing loss.

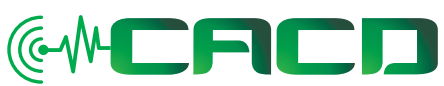

Received: January 22, 2021

Revision: April 15, 2021

Accepted: April 20, 2021

Correspondence:

Dr Udit Saxena

Department of Audiology MAA Institute of Speech \& Hearing,

Hyderabad, India

Tel: $+040-23871213$

Fax: +040-23401212

E-mail: dr.uditsaxena@gmail.com

(C) 2021 The Korean Association of SpeechLanguage Pathologists

This is an Open Access article distributed under the terms of the Creative Commons Attribution NonCommercial License (https://creativecommons.org/ licenses/by-nc/4.0/) which permits unrestricted noncommercial use, distribution, and reproduction in any medium, provided the original work is properly cited. 
In this scenario, hearing health care requires a radical service delivery.

Hearing healthcare providers must consider treatment delays with Corona-virus, given critical periods for speech- language development and the long-term impact of auditory deprivation, some audiological services should be considered essential. Fortunately, there are few "audiology emergencies.", where a patient reaches out to audiologist immediately for assistance; such as, Sudden onset hearing loss, Foreign objects in the ear, Sudden onset of vertigo, and sudden device failure (cochlear implant/hearing aid) [4].

Cochlear Implant (CI) is a medical technology that has been regarded as most efficient treatment for patients with severe to profound sensori-neural hearing loss. Approximately 400000 people worldwide receive CI; more than half of them are children. Paediatric cochlear implantation has resulted in greatly improved auditory performance and helped these young children to develop speech and language in a rapid pace. Various factors may affect the performance, in which, constant auditory stimulation, auditory verbal therapy (AVT) and proper care-maintenance are essential post implant.

There is a strong relationship between the outcomes of children with cochlear implants and the Auditory-Verbal Therapy. Dettman, Wall, Constantinescu and Dowell (2013) found better listening and spoken language outcomes for children who had undergone continuous AVT [5]. Until the present moment scientific literature concerning the common technical failures on $\mathrm{CI}$ external components and the frequency that occur are scarce. However, is very common in follow-ups, patients or their families report failures in these devices. Silverman, Schoepflin, Linstrom and Gilton (2010) reported that CI external component breakdowns are common such as; speech processor (no or intermittent or weak output, fast battery drain), cables (body worn) and microphone which needed more repair [6].

Although the pandemic had an impact on everyone, children with hearing loss create considerable challenges to their parents, particularly when there is limited access to their hearing care providers. Considering the hearing healthcare essential services, an internet-based survey was conducted on how COVID-19 had affected the services to cochlear implant users which consecutively their communication needs.

\section{METHODS}

The study was carried out during the period of June-August
2020 in the Department of Audiology, MAA Institute of Speech and Hearing, Hyderabad. A survey of 38 questions (Supplementary file) was developed and revised through several drafts with inputs from the other hearing professionals. After several revisions, a final draft was prepared for web presentation via Google forms. The draft was initially piloted on 10 individuals (5 audiologists and 5 parents of CI children). The individual observation of these respondents and their comments about the questions were used to revise the survey questions and response-choices. After the web presentation, an e-mail announcement with the link of the survey was sent to all the parents of the CI children in our database. The chronological age of the children ranged from 16 months to 19 years.

Questions were based on the common problems faced by the cochlear implant users. Nature of the questions was generally focused on how COVID-19 affected their child's communication due to limited services. The questionnaire was self-administered and the time taken would be 10-15 minutes. The initial content of the questionnaire included age, postimplant experience/age and whether unilateral or bilateral implantation, if not bilateral, uses a hearing aid in the opposite ear. Other questions discussed were; one-to-one therapy, personal protective equipments (PPE), tele- rehabilitation, AVT, home therapy, mapping, maintenance, accessories and overall communication needs. Finally, the respondents were asked for suggestions on how they would get better treatment during COVID-19 lockdown times. Respondents were asked to answer all the questions to the best of their experience. The questions were Yes/No and multiple-choice questions where choice was also permitted to report one or more problems.

\section{RESULTS}

A total of hundred and one respondents (parents of CI children) participated in the survey. Survey results can be seen in Supplementary file. The chronological age of the CI children was ranged from 16 months to 19 years (Fig. 1; Table 1) and post implant age ranged from 0.2 to 15 years. In total children, 92\% children were fitted with unilateral and $8 \%$ with bilateral implants (Table 2). Among $92 \%$ of unilateral fitting, $11 \%$ were using hearing aid in the opposite ear (Bimodal fitting) and others (89\%) were not aided with any device opposite side (Fig. 2; Table 2).

Sixty-eight\% children have completed the mandatory AVT sessions for a year and $32 \%$ were yet to complete. In those $68 \%$ 


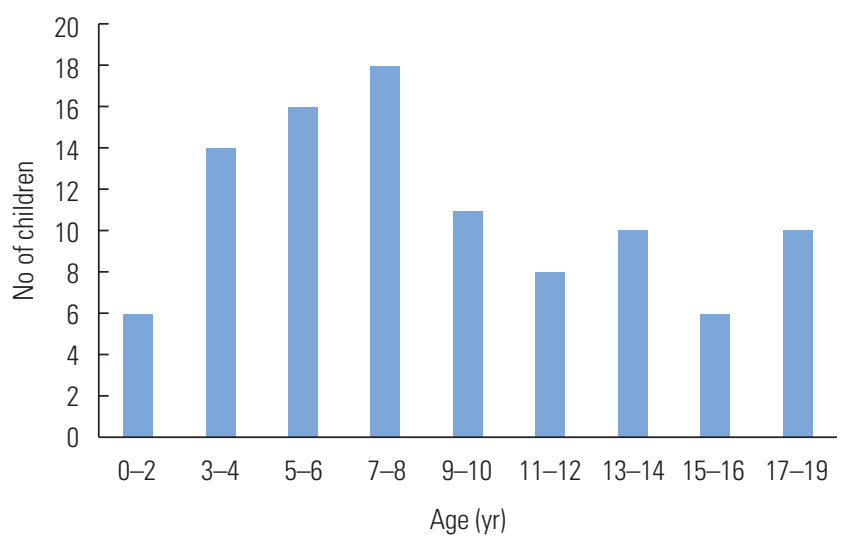

Figure 1. Distribution of $\mathrm{Cl}$ children Age wise.

Table 1. Distribution of $\mathrm{Cl}$ children according to chronological age

\begin{tabular}{lc}
\hline Chronological age (yr) & Number of Cl children \\
\hline $0-2$ & 6 \\
$3-4$ & 15 \\
$5-6$ & 16 \\
$7-8$ & 18 \\
$9-10$ & 11 \\
$11-12$ & 8 \\
$13-14$ & 10 \\
$15-16$ & 6 \\
$17-19$ & 10 \\
\hline
\end{tabular}

Table 2. Distribution of $\mathrm{Cl}$ children (\%) according to mode of fittings

\begin{tabular}{lc}
\hline Mode of fittings & Number of Cl children (\%) \\
\hline Binaural $(\mathrm{Cl})$ & 8 \\
Monaural $(\mathrm{Cl})$ & 92 \\
Bimodal $(\mathrm{Cl}+\mathrm{HA})$ & 11 (Out of $92 \%$ Monaural $\mathrm{Cl})$ \\
\hline
\end{tabular}

of children who completed 1-year therapy, majority of respondents (74\%) reported to be performing listening activities at home (Table 3). Among 32\% who have not completed 1 year of compulsorily AVT, 17\% are attending AVT and others are not attending due to limited services during COVID19 (Table 3). Those who were attending therapy, $51 \%$ were taking one-to-one therapy, $28 \%$ tele-therapy, $7 \%$ home-based program and other $14 \%$ reported to be counselled for home activities (Fig. 3, Table 4). The respondents of "the children who are under one-year compulsory therapy, but couldn't attend therapy sessions" reported that, $96 \%$ were performing activities at home, $\mathbf{8 0 \%}$ felt child is progressing and $73 \%$ felt a kind of regression in skills observed and these respondents also

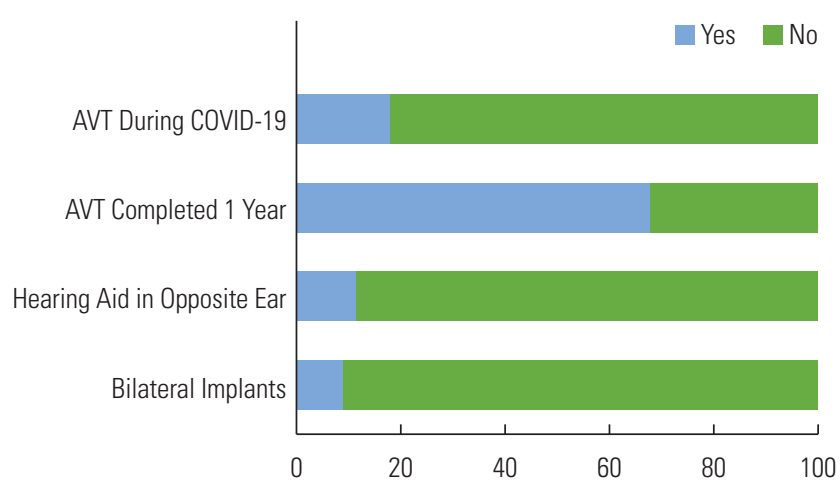

Figure 2. Distribution of $\%$ of children with device (Cl/ Hearing Aids) usage and AVT.

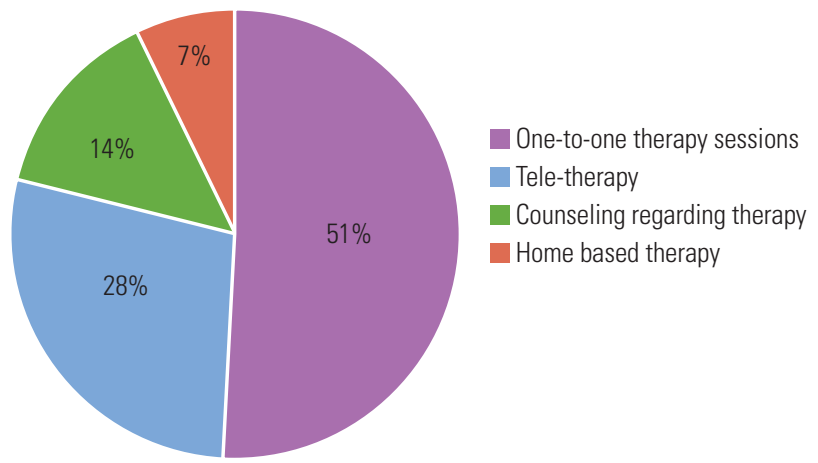

Figure 3. Chart shows the \% of Children attending therapy during COVID-19 in different mode.

Table 3. Distribution of $\mathrm{Cl}$ children (\%) according to the status of AVT

\begin{tabular}{ll}
\hline AVT status & Number of Cl children (\%) \\
\hline Completed mandatory 1-year AVT & 68 \\
$\begin{array}{l}\text { Continuing listening activities after } \\
\text { mandatory 1-year AVT is }\end{array}$ & $\begin{array}{r}74 \text { (out of 68\% Cl children who have } \\
\text { completed mandatory 1-year AVT) } \\
\text { completed }\end{array}$ \\
$\begin{array}{l}\text { 1-year mandatory AVT not } \\
\text { completed }\end{array}$ & 32 \\
Continuing AVT & 17 (out of 32\% Cl children who have \\
& not completed compulsory AVT) \\
\hline
\end{tabular}

mentioned tele-therapy services might have helped (Fig. 4).

Eleven respondents reported about the devices used for tele-therapy, in which, 8 parents used mobile phones, 2 laptop and 1 Smart TV. Further, 7 out of 11 respondents reported that their children were attentive during the tele-therapy session. The respondents also experienced few benefits of teletherapy such as; save time, increased parent involvement, avoid travel and remote access to therapist. At the same time, 


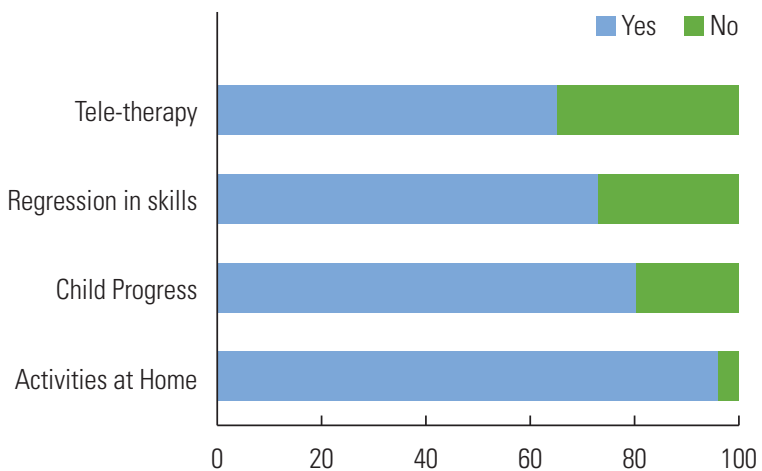

Figure 4. Percent responses- non attending therapy-during COVID-19.

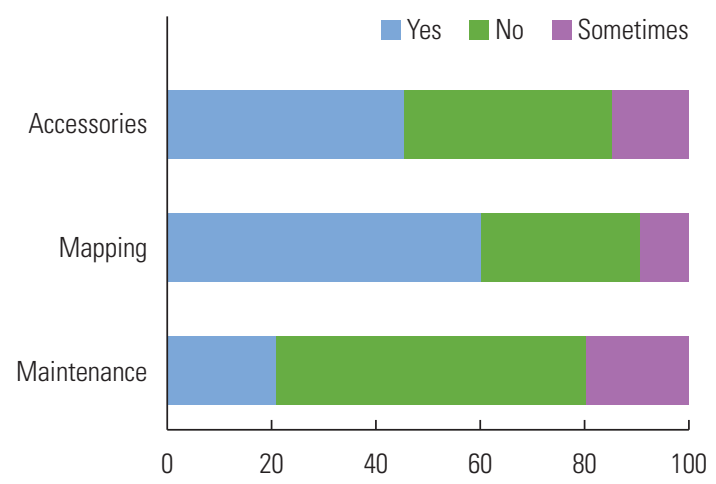

Figure 5. Percent responses of respondents who reported problems with device.

few limitations were also observed by parents such as; sound quality, poor visibility and connectivity issues. Overall, $60 \%$ of the respondents indicated tele-therapy was as effective as one-to-one therapy mode. It was also observed that, $33 \%$ respondents would prefer tele-therapy over one-to-one sessions even in normal (non-pandemic) days and $41 \%$ do not prefer and others might.

Fifty-eight percent respondents reported that they didn't face any problems with their CI device, whereas others reported some. Device accessories issues were reported by $45.4 \%$ of the respondents (Fig. 5; Table 5). Majority of the respondents (61.8\%) reported mapping issues (Fig. 5; Table 5). During one-to-one therapy, $47 \%$ children were using PPE like masks, gloves and face shields, whereas $53 \%$ were not using any protection. Out of those who were using PPEs, $60 \%$ reported to be uncomfortable wearing mask and gloves whereas $40 \%$ were comfortable. Even though, uncomfortable, $46 \%$ haven't removed PPEs during therapy and didn't stop therapy session too. The respondents even reported that, majority of the therapists (70\%) also equipped with masks, gloves and

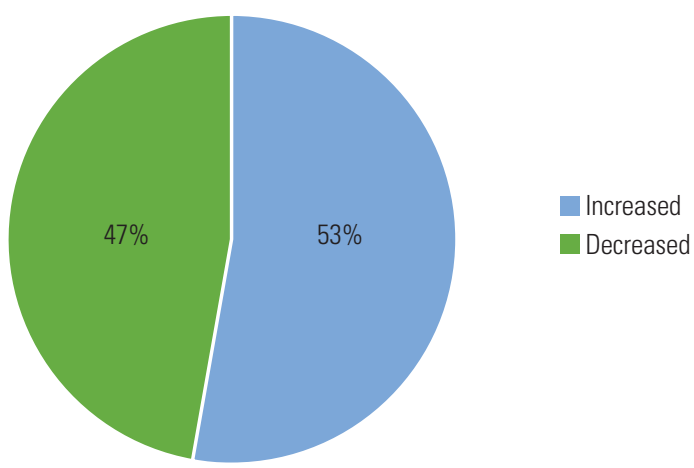

Figure 6. Overall child performance during COVID-19.

Table 4. Mode of attending AVT (out of $17 \%$ who were continuing AVT)

\begin{tabular}{lc}
\hline Mode & Number of Cl children (\%) \\
\hline One to one therapy session & 51 \\
Teletherapy & 28 \\
Supervised home based program & 7 \\
Counselled for home activities & 14 \\
\hline
\end{tabular}

Table 5. Response for $\mathrm{Cl}$ device related problem occurred during COVID

\begin{tabular}{ll}
\hline Problem & Number of Cl children (\%) \\
\hline $\begin{array}{l}\text { Device related problem was faced } \\
\text { by problem in mapping }\end{array}$ & 21.4 \\
& $\begin{array}{r}61.8 \text { (out of } 21.4 \% \mathrm{Cl} \text { children who } \\
\text { faced } \mathrm{Cl} \text { device related problem) }\end{array}$ \\
Problem in getting accessories & $\begin{array}{r}45.4 \text { (out of } 21.4 \% \mathrm{Cl} \text { children who } \\
\text { faced } \mathrm{Cl} \text { device related problem) }\end{array}$ \\
\hline
\end{tabular}

face shields. Fifty percent felt that these PPEs did not affect the performance of the child. Sixty percent of the respondents didn't find any change in their child's participation in therapy even with PPEs and they even not requested therapist to remove PPEs. Overall, $53 \%$ of the respondents observed 'Increased' communication abilities and $47 \%$ reported otherwise during COVID-19 (Fig. 6).

\section{DISCUSSION}

Although COVID-19 has adverse effect on human health, here we discuss the present pandemic condition's effect on hearing impaired, particularly focused on Cochlear Implant users. This Web based survey publicized that COVID-19 had an effect on the services to CI users and their communication needs. The focal point observed through the survey was that, the respondents (parents of the CI children) reported COVID-19 significantly affected their children in a variety of 
ways. Majority of the respondents reported their children couldn't attend AVT during lockdown. Although continuous AVT is required, immediate and intense post implant AVT is very crucial for children with cochlear implants, at least initial two years, which gives the maximum auditory information to achieve speech-language skills, keeping in mind the critical periods for speech-language development. Several studies have demonstrated a typical rate of progress in the speechlanguage development with AVT [7-9]. The outcomes of AVT were compared to the typical hearing children of same chronological age group, in which it is evidenced that AVT is an effective intervention option which improve speech perception significantly.

The respondents reported issues related to care and maintenance of the device. Literature evidenced most frequent repair issues with cochlear implants in children are related to headpiece, battery compartment, speech processor, microphone, cables, battery and battery charger [10]. However, guidance on the maintenance of these components must be carried out properly, consistently and constantly by professionals of CI programs in order to prevent technical failures of devices in a more scientific approach during these kinds of pandemic situation. Due to the lockdowns with limited services some patients couldn't attend follow-ups for their device programming, which subsequently affected their child's performance. Cochlear implants are typically programmed for each individual patient based on their auditory responses to electrical stimuli. A clinician should verify the map settings by using the patient's baseline during each programming appointment. These tasks are generally performed in a clinical set-up, where remote access to programming devices is not fully accessed yet.

However, telemedicine is an alternative that provides healthcare using telecommunication. Telemedicine is the transmission of health-related services and information by means of telecommunication technology and has been recognized as a valid and useful tool to deliver care for those who couldn't access direct services [11]. The use of telemedicine in hearing healthcare is relatively new and the applications include patient education and diagnostic services [12]. There were multiple studies that have investigated the delivery of rehabilitative hearing healthcare in a variety of settings internationally. These studies reported that programming of cochlear implants and hearing aids could be performed effectively and efficiently in a small number of subjects [13-15]. No serious adverse events were encountered; however, degradation of audio and/or video quality in the communication link hindered interactions between providers and patients [16-19]. Another important point to consider is that the face coverings are an obstacle to effective oral communication. Face masks act as a low-pass acoustic filter which interferes with speech. It was researched that, Masks had nearly no effect below 1 $\mathrm{kHz}$, but the sound pressure levels for frequencies 2,000 to7,000 $\mathrm{Hz}$ decreased up to $12 \mathrm{~dB}$ for a variety of masks [20]. The combined effect of decreased intensity, speech perceived as more muffled, will certainly cause problems for many people with hearing loss. A recent survey by [21], reported the impact of COVID-19 on access to the hearing health services for cochlear implanted children. The COVID-19 pandemic has been reported to have a considerable impact on access to the hearing health services availed by CI children. Parents and CI children are distressed due to the lack of access to services and consequent breakdown in communication.

The COVID-19 crisis has directed in a new era in hearing health care that requires a radical rethinking of service delivery in audiology. As the hearing health care community continues to compete with COVID-19, this crisis has prompted hearing professionals to think about how telemedicine (rehabilitation) can be best utilized in the future. This technology should help hearing professionals to become more integrated into the hearing health care delivery system. It has also created the momentum to rapidly formulate innovative digital (web and App- based hearing solutions) and tele-health approaches (including tools for remote device troubleshooting, counselling, fine-tuning, and tracking usage) in response to these changing situations.

\section{CONCLUSION}

COVID-19 is negatively affecting the lives of many people with hearing loss in a variety of ways. It is important that they are aware of these consequences, and have enough knowledge to do what they can to stay safe while fully communicating with the world. Although this data suggested on the problems that CI users are experiencing during these difficult times, solutions and their application in hearing health care routine are still limited and have to be tested yet. Research should be undertaken attempting to provide effective solutions to the CI users in different challenging situations. Also needed is the development of global strategies to face any such difficult condition in future. Respondents in this study were limited to our own database and as such the sample size was smaller. 
Similar studies with larger sample size are advised for better generalization of the results. Another limitation of this was that respondent were largely Indian citizen and hence worldwide study on the same issue should be implemented. Thorough research on understanding the limitations and strength of telerehabilitation is also advised, investigating this issue in details was out of the scope of this study.

\section{ACKNOWLEDGEMENTS}

The authors are delighted to thank all the parents took part in the survey.

\section{REFERENCES}

1. Jin Y, Yang H, Ji W. Virology, Epidemiology, Pathogenesis, and Control of COVID-19. Viruses. 2020;12(4):372.

2. COVID-19 coronavirus pandemic. https://www.worldometers. info/coronavirus/

3. Torales J, O'Higgins M, Castaldelli-Maia JM, Ventriglio A. The outbreak of COVID-19 coronavirus and its impact on global mental health. Int J Soc Psychiatry. 2020.

4. Julie (2020). Navigating COVID-19 with hearing loss resource guide. https://www.theaudiologymethod.com/blog/2020/4/14/ navigating-covid-19-with-hearing-loss-resource-guide

5. Dettman S, Wall E, Constantinescu G, Dowell R. Communication outcomes for groups of children using cochlear implants enrolled in auditory-verbal therapy, aural-oral, and bilingual-bicultural early intervention programs. Otology and Neurotology. 2013;34: 451-459.

6. Silverman CA, Schoepflin KR, Linstrom CJ, Gilton NS. Repair issues associated with cochlear implants in children. Otology Neurotology. 2010;31:926-931.

7. Hogan S, Stokes J, White C, Tyszkiewicz E, Woolgar A. An evaluation of auditory verbal therapy using rate of early language development as an outcome measure. Deafness and Education International. 2008;10:143-167.

8. Rhoades EA. Language progress with an auditory-verbal approach for young children with hearing loss. International Pediatrics. 2001;16:1-7.

9. Rhoades EA, Chisholm TH. Global language progress with an au- ditory-verbal approach for children who are deaf and hard of hearing. The Volta Review. 2000;102:5-24.

10. Pereira AM, Melo TM. Repair issues associated with cochlear implants external componens: influence of age and time of use. Rev. CEFAC. 2014;16:1419-1424.

11. Krumm M. Audiology telemedicine. J Telemed Telecare. 2007; 13:224-229.

12. Pearce W, Ching YCT, Dillon H. A pilot investigation into the provision of hearing services using tele-audiology to remote areas. The Australian and New Zealand Journal of Audiology. 2007;3:96100.

13. McElveen JT, Blackburn EL, Green JD Jr, McLear PW, Thimsen DJ, Wilson BS. Remote programming of cochlear implants: a telecommunications model. Otology \& Neurotology. 2010;31:10351040.

14. Kuzovkov V, Yanov Y, Levin S, Bovo R, Rosignoli M, Eskilsson G. Remote programming of MED-EL cochlear implants: users' and professionals' evaluation of the remote programming experience. Acta Oto-Laryngologica. 2014;134:709-716.

15. Eikelboom R, Jayakody D, Swanepoel D, Chang S, Atlas M. Validation of remote mapping of cochlear implants. Journal of Telemedicine and Telecare. 2014;20(4):171-177

16. Ramos A, Rodrigues C, Martinez-Beneyto P, Perez D, Gault A, Carlos Falcon J. Use of telemedicine in the remote programming of cochlear implants. Acta Oto-laryngologica. 2009;129:533-540.

17. Wesarg T, Wasowski A, Skarzynski H, Ramos A, Carlos Falcon Gonzalez J, Kyriafinis G. Remote fitting in nucleus cochlear implant recipients. Acta Oto-laryngologica. 2010;130:1379-1388.

18. Hughes ML, Goehring JL, Baudhuin JL, Diaz GR, Sanford T, Harpster R. Use of telehealth for research and clinical measures in cochlear implant recipients: a validation study. Journal of Speech, Language, and Hearing Research. 2012;55:1112-1127.

19. Geohring JL, Hughes ML, Baudhuin J, Valente DL, McCreery RW, Diaz GR, Sanford T, Harpster R. The effect of technology and testing environment on speech perception using telehealth with cochlear implant recipients. Journal of Speech, Language, and Hearing Research. 2012;55:1373-1386.

20. Goldin A, Weinstein BE, Shiman N. How do medical masks degrade speech perception? Hearing Review. 2020;27:8-9.

21. Ayas M, Ali Al Amadi AMH, Khaled D, Alwaa AM. Impact of COVID-19 on the access to hearing health care services for children with cochlear implants: a survey of parents (version 1; peer review: 2 approved) F1000Research 2020;9:690. 